\title{
Anatomia foliar e potencial hídrico na tolerância de cultivares de café ao estresse hídrico ${ }^{1}$
}

\section{Leaf anatomy and water potential in the coffee cultivars tolerance to water stress}

\author{
Luiz Antônio Batista ${ }^{2}$, Rubens José Guimarães ${ }^{3}$, Fabrício José Pereira ${ }^{4 *}$, Gladyston Rodrigues Carvalho ${ }^{5}$ e \\ Evaristo Mauro de Castro ${ }^{6}$
}

\begin{abstract}
Resumo - A cultura do café é de expressiva importância no mercado internacional, com uma produção anual de cerca de 120 milhões de sacas beneficiadas e no Brasil, é responsável pela geração de mais de dez milhões de empregos diretos e indiretos. $\mathrm{O}$ estresse hídrico é um fator ambiental que pode ser extremamente prejudicial para a cultura do café, sendo que a seleção de cultivares tolerantes é de grande importância, principalmente diante da expansão da cafeicultura brasileira para áreas consideradas marginais para o cultivo do café por estarem sujeitos à deficiência hídrica. Nesse trabalho foram avaliadas 15 cultivares de Coffea arabica quanto ao status hídrico e às características da estrutura interna das folhas, verificando quais dessas cultivares são potencialmente mais eficientes em tais condições. Dentre as cultivares estudadas destacam-se a Bourbon Amarelo e a Catimor como potencialmente mais eficientes em condições de estresse hídrico por possuírem: maior potencial hídrico, cutícula mais espessa, maior proporção de parênquima paliçádico, maior espessura da nervura central e maior densidade estomática em relação às demais variáveis. Dessa forma, as cultivares Bourbon Amarelo e Catimor são potencialmente mais eficientes na redução da transpiração, fotossíntese e translocação de fotossintatos em condições de estresse hídrico, sendo mais indicadas ao plantio em regiões sujeitas a maiores déficits hídricos em relação às demais cultivares estudadas.
\end{abstract}

Palavra-chave - Coffea arábica. Plasticidade anatômica. Deficiência hídrica.

\begin{abstract}
Coffee yield has a great importance to the international market with a 120 million 60-kilogram bags and in Brazil it produces 10 million of direct and indirect jobs. Water stress is one of the most important factors to the crop yield, and so, the selection of tolerant cultivars is of great importance in the places under water stress. In this work, 15 Coffea arabica cultivars were evaluated about the water status and leaf anatomy to indicate the most tolerant Cultivars under water stress. The Bourbon Amarelo and Catimor were the most efficient under water stress, because these varieties have thicker cuticle, more palicade parenchyma, bigger central bundle sheath, and higher stomatal density. So, these Cultivars can be more potentially more efficient to reduce the transpiratory rate, to improve the photosynthesis and photosynthates translocation under water stress, and these varieties can be more indicated under water stress against the other cultivars.
\end{abstract}

Key words - Coffea Arabica. Anatomical plasticity. Water deficit.

\footnotetext{
* Autor para correspondência

'Recebido para publicação em 23/10/2009; aprovado em 07/08/2010

Parte da Tese de Doutorado do primeiro autor apresentado ao Programa de Pós-graduação em Agronomia-Fitotecnia da UFLA

${ }^{2}$ Programa de Pós-Graduação em Fitotecnia, Departamento de Agricultura, Universidade Federal de Lavras, Campus Universitário, Caixa Postal 3.037, Lavras-MG, Brasil, CEP 37200-000, luizanbatista@yahoo.com.br

${ }^{3}$ Departamento de Agricultura, Universidade Federal de Lavras, Campus Universitário, Caixa Postal 3.037, Lavras-MG, Brasil, rubensjg@ufla.br

${ }^{4}$ Programa de Pós-Graduação em Fisiologia Vegetal, Departamento de Biologia, Universidade Federal de Lavras, Campus Universitário, Caixa Postal

3.037, Lavras-MG, Brasil, 37.200-000, fjprock@hotmail.com

${ }^{5}$ Empresa de Pesquisa Agropecuária de Minas Gerais- EPAMIG, Centro Tecnológico do Sul de Minas, Campus da Universidade Federal de Lavras,

Caixa Postal 176, Lavras-MG, Brasil, 37.200-000, carvalho@epamig.br

6Departamento de Biologia, Universidade Federal de Lavras, Campus Universitário, Caixa Postal 3.037, Lavras-MG, Brasil, 37.200-000, emcastro@ufla.br
} 


\section{Introdução}

O cultivo do café é de extrema importância para a balança comercial brasileira(COELHO etal., 2009), edestacase historicamente no desenvolvimento do País (MOREIRA et al., 2004). As características dessa cultura são dependentes do serviço braçal, e, dessa forma, geram muitos serviços diretos no campo (MELLO, 2001). Além dos empregos diretos, a cultura gera postos de trabalho indiretamente nas cidades, nas fases de comercialização e beneficiamento do produto (MOREIRA et al., 2004). A produção anual de café no Brasil conta com uma média de 40 milhões de sacas, sendo que as exportações brasileiras correspondem a aproximadamente $30 \%$ do total mundial (BRASIL, 2009).

As plantas cultivadas estão expostas constantemente a estresses abióticos que comprometem a produção, dentre esses, na região nordeste do país, podem ocorrer períodos de seca decorrentes de precipitações pluviométricas irregulares e veranicos (PINTO et al., 2008), sendo que um dos fatores limitantes para a produção vegetal no nordeste brasileiro pode ser o estresse hídrico (MENDES et al., 2007). A região Nordeste, particularmente o estado da Bahia, pode representar uma região importante para expansão da cafeicultura no país, contando com técnicas de manejo e irrigação adequadas, que podem gerar atualmente, de 60-80 sacas por hectare (BLISKA et al., 2009). A produtividade do cafeeiro é fortemente influenciada pelo suprimento adequado de água e de nutrientes (COELHO et al., 2009). Dessa forma, o conhecimento do status hídrico do cafeeiro é essencial ao entendimento do potencial produtivo das cultivares, por este fator afetar diretamente a produtividade (Da MATTA, 2004).

As alterações nas relações hídricas no cafeeiro são de extrema importância, pois mesmo pequenas modificações nas condições hídricas podem reduzir intensamente o crescimento, mesmo não ocorrendo as respostas típicas das plantas nessas condições, como a murcha das folhas (SILVA et al., 2008). Portanto, características da estrutura interna das folhas podem ser importantes para discriminar o nível de tolerância para o estresse hídrico.

Fatores ambientais influenciam diretamente a anatomia foliar, sendo que a condição hídrica é um dos fatores mais importantes para o desenvolvimento foliar (CASTRO et al., 2009) e a anatomia foliar se destaca nas relações com a produção vegetal (SILVA et al., 2005). A anatomia foliar do cafeeiro demonstra plasticidade para fatores como as condições de radiação, alterando as espessuras do parênquima paliçádico e esponjoso, dimensões estomáticas entre outras (NASCIMENTO et al., 2006; PINHEIRO et al., 2005; RAMIRO et al., 2004).
Em trabalho realizado sobre avaliações anatômicas foliares em mudas de café 'Catuaí' e 'Siriema' submetidas ao estresse hídrico, Grisi et al. (2008) não encontraram modificações na anatomia foliar do cafeeiro sob estresse hídrico. Entretanto, nessas mesmas condições encontraram diferenças nas espessuras do clorênquima, limbo, além da densidade e dimensões estomáticas de outras cultivares e, essas características permitiram diferenciar a capacidade de tolerância, com vantagem para os genótipos 'Siriema' e 'Catuaí' (GRISI et al., 2008).

Portanto, a identificação de cultivares com maior potencial para a tolerância ao estresse hídrico é de extrema importância para a expansão da cafeicultura no Brasil, como a região Nordeste do país e o Norte de Minas Gerais. Dessa forma, esse trabalho teve como objetivo verificar o potencial de tolerância ao déficit hídrico em plantas de quinze diferentes cultivares de Coffea arabica, pela caracterização do status hídrico e das características da estrutura interna das folhas.

\section{Material e métodos}

O experimento foi conduzido em campo, na fazenda experimental da Empresa Agropecuária de Minas Gerais (Epamig), em São Sebastião do Paraíso, MG. Foramutilizadas 15 cultivares selecionadas pelo programa de melhoramento genético do cafeeiro de Minas Gerais (TAB. 1).

Tabela 1 - Cultivares de café do programa de melhoramento genético do cafeeiro em Minas Gerais utilizadas como tratamentos

\begin{tabular}{cc}
\hline Número & Cultivar \\
\hline 1 & Obatã \\
2 & Catucaí Amarelo 2 SL \\
3 & Paraíso MG 1 \\
4 & Pau- Brasil MG 1 \\
5 & Palma 2 \\
6 & Catuaí IAC 99 \\
7 & Rubi MG 1192 \\
8 & Topázio MG 1190 \\
9 & Bourbon Amarelo LCJ 06 \\
10 & Mundo Novo 379-19 \\
11 & Icatú Amarelo IAC 3282 \\
12 & Catiguá MG 2 \\
13 & Siriema Vermelho \\
14 & Sabiá \\
15 & Catimor UFV 5390 \\
\hline
\end{tabular}


$\mathrm{O}$ delineamento experimental utilizado foi em blocos casualizados, no espaçamento de 3,0 x 1,5 metros, com 15 tratamentos (genótipos de cafeeiros), e com 3 repetições. $\mathrm{O}$ experimento foi instalado em fevereiro de 2005, seguindo as recomendações de plantio, formação da lavoura e tratos culturais, de acordo com Guimarães et al. (2002). A correção do solo e as adubações de NPK foram realizadas de acordo com as recomendações da quinta aproximação da Comissão de Fertilidade do Solo do Estado de Minas Gerais-CFSMG (GUIMARÃES; MENDES, 1999), com base em resultados das análises de solo. Os tratamentos fitossanitários foram realizados preventivamente para o controle das principais doenças.

Avaliou-se o potencial hídrico em folhas completamente expandidas de todas as plantas, sendo que as avaliações foram realizadas às 6 horas, em dias claros, com a bomba de Sholander. As folhas foram colhidas em ramos plagiotrópicos no terço superior das plantas, localizados no quarto nó a partir do ápice do ramo (SILVA et al., 2008).

Para o estudo anatômico também foram coletadas folhas completamente expandidas do quarto nó de ramos do terço superior das plantas, fixadas em F.A.A. ${ }_{70}$, por 72 horas e após esse período, conservadas em etanol $70 \%$ para posteriores análises no Laboratório de Anatomia Vegetal do Departamento de Biologia da Universidade Federal de Lavras, MG. Foram realizadas secções transversais na região mediana das folhas, com auxílio do micrótomo de mesa. Em seguida, as secções foram clarificadas em solução a 50\% de hipoclorito de sódio, lavadas em água destilada e submetidas ao processo de coloração com solução de safrablau (safranina 1\% e azul de astra $0,1 \%$ na proporção de 7:3) tendo as lâminas sido montadas em glicerina a 50\% (MELO et al., 2007). Análises referentes à espessura dos tecidos foliares foram feitas a partir de três medições para cada parâmetro analisado, perfazendo um total de 15 medições por amostra.

As secções paradérmicas foram obtidas na epiderme da face abaxial, na região mediana foliar, utilizando-se lâmina de aço. Posteriormente, as secções foram clarificadas em solução a $50 \%$ de hipoclorito de sódio, lavadas em água destilada e coradas com safranina $1 \%$ (MELO et al., 2007), tendo as lâminas sido montadas em glicerina a $50 \%$.

As fotomicrografias foram realizadas, utilizandose uma câmera digital Canon PowerShot A620 acoplada ao microscópio KEN-A-VISION TT18. As análises anatômicas foram realizadas utilizando-se o Software Image Tool da UTHSCSA.

Para as avaliações relativas à caracterização dos estômatos (densidade estomática, diâmetros polar e equatorial) foram observados quatro campos, totalizando 20 campos por tratamento (cinco folhas por tratamento).

Para análise estatística foram realizadas análises de variância utilizando-se o teste de Scott-Knott a 5\% de probabilidade para o estudo das médias, com auxílio do Software SISVAR.

\section{Resultados e discussão}

Os maiores potenciais hídricos foram observados para as cultivares Catimor UFV 5390, Bourbon Amarelo LCJ 06, Obatã, Catucaí amarelo 2 SL, Pau Brasil MG 1, Mundo Novo 379-19 e Icatu Amarelo IAC 3282 sendo que esses valores foram próximos a -0,9 MPa (Tabela 2). As cultivares Paraíso MG 1, Palma 2, Catucaí IAC 99, Rubi MG 1192, Topázio MG 1190, Catiguá MG 2, Siriema Vermelho e Sabiá, tiveram potenciais hídricos em média 1,7 vezes menores, correspondendo às menores médias observadas para essa característica (TAB. 2). Silva et al. (2008) verificaram valores de potencial hídrico foliar que eram bastante superiores aos encontrados no presente trabalho quando utilizando irrigação, contudo, mesmo sem irrigação, as cultivares Catimor e Bourbon Amarelo demonstraram valores próximos aos cafeeiros irrigados no trabalho de Silva et al. (2008). Valores de potencial hídrico até -1,5 MPa parecem não afetar a fotossíntese em condições de campo (Da MATTA et al., 2007; GOLBERG et al., 1988). Apesar de possivelmente não ter ocorrido efeitos na fotossíntese, pois todas as cultivares apresentaram valores acima de -1,5 MPa (TAB. 2), podem ter ocorrido diferenças no crescimento decorrentes da redução no potencial hídrico, visto que a água é um componente essencial para a expansão celular (CASTRO et al., 2009) e, mesmo a época de irrigação diferente pode influenciar na produtividade de cafeeiros (COELHO et al., 2009). Dessa forma, estádios como o desenvolvimento dos frutos podem ser prejudicados nessas cultivares e, as cultivares de potencial hídrico mais elevado podem ser mais aptas ao desenvolvimento normal e produção em condições de estresse hídrico.

Os dados da anatomia foliar das cultivares analisadas permitem inferir tendências que explicam as variações no potencial hídrico das mesmas. A cultivar Bourbon Amarelo, que exibiu alto potencial hídrico se encontra entre as cultivares com maior espessura de cutícula de ambas as faces da epiderme, enquanto a cultivar Catiguá, com as menores espessuras da cutícula se encontra na faixa com os menores potenciais hídricos (TAB. 2 e 3 ). Devido à sua natureza lipídica, a cutícula mais espessada pode evitar a perda de água excessiva por transpiração, sendo, portanto, um importante mecanismo de tolerância ao déficit hídrico (CASTRO et al., 2009). Dessa forma, o espessamento da cutícula pode permitir à cultivar Bourbon Amarelo uma 
maior tolerância ao estresse hídrico, indicando uma baixa adaptabilidade da cultivar Catiguá a essas condições. Essas interpretações podem ser estendidas para as outras cultivares constantes das Tabelas 2 e 3. Diferenças nas espessuras foliares são características dos genótipos e, foram verificadas para diferentes espécies e hídridos de café sob estresse hídrico (RAMIRO et al., 2004).

A epiderme da face abaxial não se modificou nas diferentes cultivares (TAB. 3), entretanto, a epiderme da face adaxial demonstrou modificações, sendo que das cultivares que exibiram maior espessura de epiderme, apenas a cultivar Catimor está na faixa de maior potencial hídrico (TAB. 2 e 3). Também Grisi et al. (2008), estudando a caracterização de folhas de duas cultivares de cafeeiro sob condições de estresse hídrico, quando comparados com a situação em que não houve estresse hídrico, não observaram diferenças significativas para os valores da epiderme abaxial. A incidência de radiação, de forma geral, é maior na face adaxial das folhas e, por isso, as respostas da face abaxial podem não ser tão facilmente observadas como acontece na face adaxial. Contudo, como observado no trabalho de Grisi et al. (2008) e nas Tabelas 2 e 3, a cutícula parece ser mais importante para a redução da transpiração do que a espessura da epiderme nas cultivares estudadas, e por isso as cultivares que demonstraram maiores espessuras de epiderme, exceto a Catimor não se encontram dentre aquelas com melhor status hídrico.
Tabela 2 - Variações no potencial hídrico nas 15 cultivares de Coffea arabica analisadas

\begin{tabular}{cc}
\hline Cultivar & Potencial hídrico $\psi(\mathrm{MPa})$ \\
\hline Obatã & $-0,80 \mathrm{a}$ \\
Catucaí Amarelo 2 SL & $-0,87 \mathrm{a}$ \\
Paraíso MG 1 & $-1,35 \mathrm{~b}$ \\
Pau- Brasil MG 1 & $-0,63 \mathrm{a}$ \\
Palma 2 & $-1,42 \mathrm{~b}$ \\
Catuaí IAC 99 & $-1,55 \mathrm{~b}$ \\
Rubi MG 1192 & $-1,10 \mathrm{~b}$ \\
Topázio MG 1190 & $-1,17 \mathrm{~b}$ \\
Bourbon Amarelo LCJ 06 & $-1,00 \mathrm{a}$ \\
Mundo Novo 379-19 & $-1,00 \mathrm{a}$ \\
Icatú Amarelo IAC 3282 & $-0,90 \mathrm{a}$ \\
Catiguá MG 2 & $-1,25 \mathrm{~b}$ \\
Siriema Vermelho & $-1,37 \mathrm{~b}$ \\
Sabiá & $-1,20 \mathrm{~b}$ \\
Catimor UFV 5390 & $-0,90 \mathrm{a}$ \\
\hline
\end{tabular}

Médias seguidas de mesma letra na coluna não diferem entre si pelo teste de Scott-Knott a 5\% de probabilidade

Tabela 3 - Variações na espessura dos tecidos foliares (em $\mu \mathrm{m})$ e na proporção em plantas de 15 diferentes cultivares de Coffea arabica

\begin{tabular}{lcccccccc}
\hline Cultivares & CTA & CTB & EAD & EAB & PPA & PES & LIM & NER \\
\hline Bourbon & $4,6 \mathrm{a}$ & $4,5 \mathrm{a}$ & $20,9 \mathrm{~b}$ & $16,1 \mathrm{a}$ & $75,0 \mathrm{a}$ & $165,8 \mathrm{~b}$ & $295,0 \mathrm{c}$ & $1257,4 \mathrm{~b}$ \\
Catiguá & $3,4 \mathrm{c}$ & $2,8 \mathrm{~b}$ & $24,4 \mathrm{a}$ & $17,1 \mathrm{a}$ & $68,8 \mathrm{~b}$ & $160,6 \mathrm{~b}$ & $285,1 \mathrm{c}$ & $1320,4 \mathrm{a}$ \\
Catimor & $5,0 \mathrm{a}$ & $3,5 \mathrm{~b}$ & $23,0 \mathrm{a}$ & $15,4 \mathrm{a}$ & $72,9 \mathrm{a}$ & $176,8 \mathrm{~b}$ & $304,6 \mathrm{~b}$ & $1229,6 \mathrm{~b}$ \\
Catuaí & $4,1 \mathrm{~b}$ & $3,9 \mathrm{a}$ & $20,9 \mathrm{~b}$ & $17,3 \mathrm{a}$ & $65,1 \mathrm{~b}$ & $170,6 \mathrm{~b}$ & $292,1 \mathrm{c}$ & $1195,8 \mathrm{~b}$ \\
Catucaí & $4,8 \mathrm{a}$ & $4,0 \mathrm{a}$ & $21,2 \mathrm{~b}$ & $15,9 \mathrm{a}$ & $67,6 \mathrm{~b}$ & $186,2 \mathrm{a}$ & $305,4 \mathrm{~b}$ & $1231,9 \mathrm{~b}$ \\
Icatu & $4,5 \mathrm{~b}$ & $4,3 \mathrm{a}$ & $20,2 \mathrm{~b}$ & $16,0 \mathrm{a}$ & $69,4 \mathrm{~b}$ & $159,6 \mathrm{~b}$ & $281,9 \mathrm{c}$ & $1219,5 \mathrm{~b}$ \\
M. Novo & $4,9 \mathrm{a}$ & $4,1 \mathrm{a}$ & $19,9 \mathrm{~b}$ & $17,6 \mathrm{a}$ & $64,5 \mathrm{~b}$ & $162,2 \mathrm{~b}$ & $281,6 \mathrm{c}$ & $994,6 \mathrm{~d}$ \\
Obatã & $4,5 \mathrm{~b}$ & $4,1 \mathrm{a}$ & $19,6 \mathrm{~b}$ & $16,3 \mathrm{a}$ & $76,8 \mathrm{a}$ & $192,0 \mathrm{a}$ & $321,2 \mathrm{~b}$ & $1391,6 \mathrm{a}$ \\
Palma & $5,1 \mathrm{a}$ & $4,4 \mathrm{a}$ & $24,4 \mathrm{a}$ & $17,6 \mathrm{a}$ & $81,0 \mathrm{a}$ & $206,4 \mathrm{a}$ & $346,8 \mathrm{a}$ & $1124,7 \mathrm{c}$ \\
Paraíso & $5,0 \mathrm{a}$ & $4,5 \mathrm{a}$ & $18,3 \mathrm{~b}$ & $16,7 \mathrm{a}$ & $68,4 \mathrm{~b}$ & $170,1 \mathrm{~b}$ & $291,0 \mathrm{c}$ & $1179,4 \mathrm{c}$ \\
Pau Brasil & $4,3 \mathrm{~b}$ & $4,5 \mathrm{a}$ & $20,1 \mathrm{~b}$ & $16,5 \mathrm{a}$ & $60,6 \mathrm{~b}$ & $162,7 \mathrm{~b}$ & $276,4 \mathrm{c}$ & $1085,1 \mathrm{~d}$ \\
Rubi & $4,9 \mathrm{a}$ & $4,7 \mathrm{a}$ & $19,7 \mathrm{~b}$ & $15,6 \mathrm{a}$ & $63,2 \mathrm{~b}$ & $155,8 \mathrm{~b}$ & $272,0 \mathrm{c}$ & $1170,9 \mathrm{c}$ \\
Sabiá & $5,1 \mathrm{a}$ & $4,1 \mathrm{a}$ & $20,7 \mathrm{~b}$ & $15,4 \mathrm{a}$ & $73,0 \mathrm{a}$ & $195,8 \mathrm{a}$ & $322,1 \mathrm{~b}$ & $1152,5 \mathrm{c}$ \\
Siriema & $4,8 \mathrm{a}$ & $4,6 \mathrm{a}$ & $20,3 \mathrm{~b}$ & $16,9 \mathrm{a}$ & $72,3 \mathrm{a}$ & $182,5 \mathrm{a}$ & $309,4 \mathrm{~b}$ & $1301,2 \mathrm{a}$ \\
Topázio & $5,2 \mathrm{~b}$ & $4,3 \mathrm{a}$ & $24,9 \mathrm{a}$ & $15,7 \mathrm{a}$ & $76,9 \mathrm{a}$ & $149,3 \mathrm{~b}$ & $284,1 \mathrm{c}$ & $1074,0 \mathrm{~d}$ \\
\hline
\end{tabular}

$\mathrm{CTA}=$ espessura da cutícula da face adaxial das folhas; $\mathrm{CTB}=$ espessura da cutícula da face abaxial das folhas; $\mathrm{EAD}=$ espessura da epiderme da face adaxial; $\mathrm{EAB}$ = espessura da epiderme da face abaxial; PPA = espessura do parênquima paliçádico; $\mathrm{PES}$ = espessura do parênquima esponjoso; LIM = espessura do limbo; NER = espessura da nervura central. Médias seguidas de mesma letra na coluna não diferem entre si pelo teste de Skottknott para $\mathrm{P}<0,05$ 
A espessura do parênquima paliçádico exibiu diferenças entre as cultivares analisadas (TAB. 3). As cultivares de maior potencial hídrico (Bourbon Amarelo e Catimor) tiveram os maiores resultados para a espessura do parênquima paliçádico, seguidos de outras cultivares e, aquelas como a Catiguá, com baixo potencial hídrico também tenderam a ter uma menor espessura de parênquima paliçádico. O parênquima paliçádico está intimamente relacionado com a fotossíntese e, um maior desenvolvimento desse tecido pode permitir maior fixação de $\mathrm{CO}_{2}$ com uma abertura dos estômatos em curto espaço de tempo (CASTRO et al., 2009) fazendo com que a eficiência do uso da água aumente por reduzir a transpiração, e assim, tendo maiores condições de sobreviver e de reproduzir em um ambiente de estresse hídrico (JONES, 1992).

$\mathrm{O}$ parênquima esponjoso aumentou em espessura apenas em cultivares com menores potenciais hídricos (TAB. 2 e 3). Dessa forma, o investimento das cultivares de alto desempenho em condições de estresse hídrico, dentre as cultivares analisadas, a Bourbon Amarelo e a Catimor, parecem ter desenvolvido mais seus parênquimas paliçádicos em detrimento do esponjoso. Assim, possivelmente essas plantas proporcionaram uma fotossíntese mais rápida do que o fato de potencialmente armazenarem o $\mathrm{CO}_{2}$ no parênquima esponjoso (CASTRO et al., 2009).

A maior espessura do limbo foliar na cultivar Palma foi devido às maiores espessuras da cutícula e epiderme da face adaxial, e parênquimas paliçádico e esponjoso. Segundo Castro et al. (2009) alterações ocasionadas pelo estresse hídrico estão relacionadas a outros fatores de estresse, como altas temperaturas e excesso de radiação solar. Plantas de café submetidas a condições de maior intensidade de radiação, sem sombreamento, apresentaram maiores médias da espessura do limbo foliar, típicas de folhas de sol, que respondem primariamente auma limitação hídrica pelo excesso de temperatura (NASCIMENTO et al., 2006). São características que visam minimizar o aquecimento com o aumento da espessura dos parênquimas clorofilianos a fim de que haja absorção, canalização e dispersão da luz, não prejudicando as atividades foliares. Segundo o mesmo autor, células alongadas no parênquima estão relacionadas à redução na resistência do mesofilo ao dióxido de carbono e correlacionadas com aumento de fatores que são potencialmente limitantes do processo fotossintético, como a atividade enzimática, transporte de elétrons e condutância estomática.

Analisando as cultivares que se destacam como potenciais para a produção em condições de estresse hídrico pelas características anteriores (Bourbon amarelo e Catimor), verifica-se que essas cultivares apresentaram um aumento na espessura da nervura central (TAB. 3) em relação à maioria das demais cultivares. $\mathrm{O}$ aumento da nervura central pode ser relacionado com um maior fluxo de fotossintatos e água na planta. Assim, é possível a translocação de mais água necessária à manutenção da turgidez celular nas folhas, fato essencial para o correto metabolismo. O maior espessamento do floema permite uma maior translocação de carboidratos (PEREIRA et al., 2008), que são importantes para a manutenção do crescimento da planta e para o desenvolvimento dos frutos em uma relação fonte-dreno (CASTRO et al., 2009).

Para o diâmetro polar dos estômatos não houve diferença significativa para as cultivares estudadas, da mesma forma que para a relação diâmetro polar/equatorial (TAB. 4), que indica o formato dos estômatos e, quando apresenta maior valor, indica uma maior funcionalidade do estômato, por seu formato elipsóide (CASTRO et al., 2009). Para o diâmetro equatorial dos estômatos, os maiores valores foram encontrados nas cultivares Sabiá, Topázio, Siriema e Icatu. (TAB. 4). No entanto, esse aumento não foi significativo para alterar a funcionabilidade, dada pela relação DP/DE.

Segundo Castro et al. (2009) condições ambientais como estresse hídrico alteram o tamanho e a densidade dos estômatos, com o intuito de auxiliar a planta na tolerância desta condição. Em ambientes com menor disponibilidade hídrica, verifica-se diminuição no tamanho dos estômatos, para que haja uma menor perda de água da planta para o ambiente pela transpiração, havendo o simultâneo aumento de sua densidade, contribuindo para o equilíbrio das trocas gasosas. Esses fatos podem compensar a perda de área foliar que é comum em plantas sob estresse hídrico, como relatado por Pinto et al. (2008), que verificaram uma redução na área foliar e número de folhas de diferentes espécies sob estresse hídrico, fato também relatado por Mendes et al. (2007), que verificaram ainda uma redução na produção de frutos e sementes para o feijão de corda sob estresse hídrico. Os estômatos se destacam na produção vegetal por serem a porta de entrada do $\mathrm{CO}_{2}$ (SILVA et al., 2005).

A densidade estomática foi maior na cultivar Bourbon Amarelo e, um pouco mais reduzida na cultivar Catimor (FIG. 1 e TAB. 4), contudo, essas permaneceram com suas médias superiores às demais cultivares. $\mathrm{O}$ aumento na densidade estomática pode ser relacionado com uma maior capacidade das plantas em captar o $\mathrm{CO}_{2}$ da atmosfera e, dessa forma, aumentar a eficiência fotossintética por permitir que mais desse gás seja fixado (CASTRO et al., 2009). Da Matta (2004), cita que uma das maiores restrições para a produção de café sob estresse hídrico pode ser a queda na assimilação de $\mathrm{CO}_{2}$, decorrente da restrição na condutância estomática. Dessa forma, as cultivares Bourbon Amarelo e Catimor podem ser mais eficientes nas condições estudadas, pois podem permitir que mais carbono seja fixado em relação às demais cultivares, aumentando sua produção. 
Tabela 4 - Diferenças nas características estomáticas de 15 cultivares de Coffea arabica

\begin{tabular}{lcccc}
\hline \multicolumn{1}{c}{ Cultivares } & DP & DE & DP/DE & DEN \\
\hline Bourbon amarelo & $24,3 \mathrm{a}$ & $16,9 \mathrm{~b}$ & $1,5 \mathrm{a}$ & $244,7 \mathrm{a}$ \\
Catiguá & $24,9 \mathrm{a}$ & $17,1 \mathrm{~b}$ & $1,5 \mathrm{a}$ & $179,7 \mathrm{c}$ \\
Catimor & $23,2 \mathrm{a}$ & $16,0 \mathrm{~b}$ & $1,5 \mathrm{a}$ & $216,0 \mathrm{~b}$ \\
Catuaí & $24,9 \mathrm{a}$ & $16,7 \mathrm{~b}$ & $1,5 \mathrm{a}$ & $197,8 \mathrm{c}$ \\
Catucaí & $25,7 \mathrm{a}$ & $16,7 \mathrm{~b}$ & $1,6 \mathrm{a}$ & $225,5 \mathrm{~b}$ \\
Icatu & $23,6 \mathrm{a}$ & $17,3 \mathrm{a}$ & $1,4 \mathrm{a}$ & $191,6 \mathrm{c}$ \\
Mundo Novo & $23,9 \mathrm{a}$ & $16,7 \mathrm{~b}$ & $1,4 \mathrm{a}$ & $206,3 \mathrm{~b}$ \\
Obatã & $32,5 \mathrm{a}$ & $16,1 \mathrm{~b}$ & $2,0 \mathrm{a}$ & $208,2 \mathrm{~b}$ \\
Palma & $25,4 \mathrm{a}$ & $16,4 \mathrm{~b}$ & $1,6 \mathrm{a}$ & $184,1 \mathrm{c}$ \\
Paraíso & $25,7 \mathrm{a}$ & $17,0 \mathrm{~b}$ & $1,5 \mathrm{a}$ & $211,8 \mathrm{~b}$ \\
Pau Brasil & $24,2 \mathrm{a}$ & $16,6 \mathrm{~b}$ & $1,5 \mathrm{a}$ & $187,3 \mathrm{c}$ \\
Rubi & $24,3 \mathrm{a}$ & $16,6 \mathrm{~b}$ & $1,5 \mathrm{a}$ & $217,0 \mathrm{~b}$ \\
Sabiá & $25,8 \mathrm{a}$ & $18,1 \mathrm{a}$ & $1,4 \mathrm{a}$ & $169,4 \mathrm{~d}$ \\
Siriema & $26,3 \mathrm{a}$ & $17,7 \mathrm{a}$ & $1,5 \mathrm{a}$ & $189,2 \mathrm{c}$ \\
Topázio & $25,5 \mathrm{a}$ & $17,9 \mathrm{a}$ & $1,4 \mathrm{a}$ & \\
\hline
\end{tabular}

$\mathrm{DP}=$ diâmetro polar dos estômatos $(\mathrm{em} \mu \mathrm{m}) ; \mathrm{DE}=$ diâmetro equatorial dos estômatos (em $\mu \mathrm{m})$; DP/DE = relação entre os diâmetros estomáticos; $\mathrm{DEN}=$ densidade estomática $\left(\mathrm{n}^{\circ}\right.$ por $\left.\mathrm{mm}^{2}\right)$. Médias seguidas de mesma letra na coluna não diferem entre si pelo teste de Scott-Knott para $\mathrm{P}<0,05$

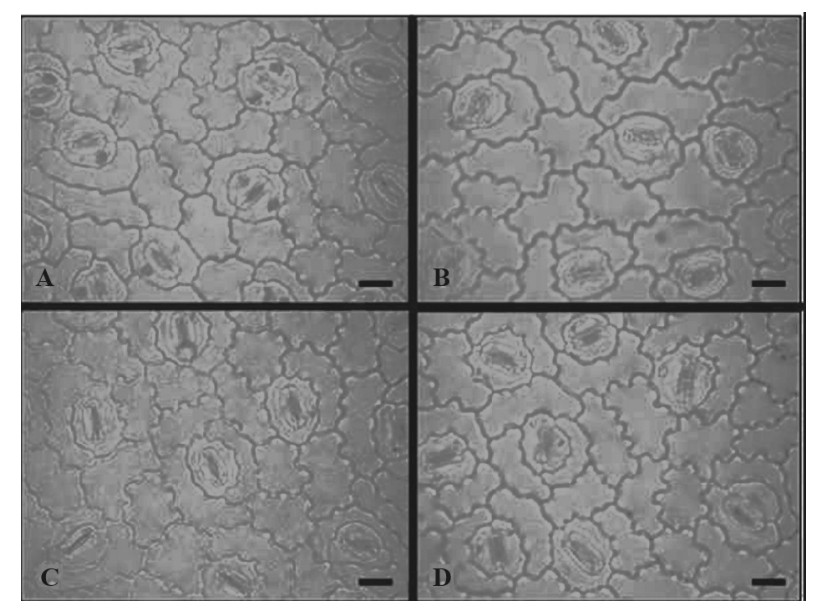

Figura 1 - Fotomicrografias de secções paradérmicas da epiderme da face abaxial da folha de quatro cultivares de Coffea arabica. (A - Bourbon Amarelo LCJ 06; B - Catimor UFV; C - Icatu Amarelo IAC 3282; C -Topázio MG 1190). Barra $=20 \mu \mathrm{m}$

Assim, as diferentes cultivares apresentam diferentes respostas potenciais ao déficit hídrico, sendo que nessas condições as cultivares Bourbon Amarelo e Catimor parecem ser as de melhores condições hídricas. Com a necessidade de expansão das fronteiras do cultivo de café (BLINSKA et al., 2009) essas podem ser potenciais cultivares para a utilização no Nordeste Brasileiro e no Norte de Minas Gerais, gerando empregos e renda, pois essas atividades requerem muita mão de obra (MELLO, 2001). Pode ainda possibilitar estudos de monitoramento que visem à previsão de safra com essas cultivares nas áreas selecionadas, contribuindo para um melhor desempenho do mercado cafeeiro, que é desejável como a questão levantada por Moreira et al. (2004). Essas cultivares se destacam também por características foliares mais adaptadas a condições de déficit hídrico como: cutícula mais espessa, maior proporção de parênquima paliçádico, nervura central mais desenvolvida e maior densidade estomática, que permitem às plantas dessas cultivares reduzir a transpiração, possuir maior eficiência fotossintética e maior translocação de fotossintatos, sendo potencialmente mais produtivas que as demais cultivares nessas condições.

\section{Conclusões}

1. As características anatômicas encontradas nas cultivares Bourbon Amarelo IAC 06 e Catimor UFV 5390 são fatores indicativos para uma seleção de materiais tolerantes ao déficit hídrico em áreas aptas ao cultivo, porém com restrições hídricas;

2. A avaliação do potencial hídrico e a caracterização anatômica das plantas poderá ser um importante instrumento no apoio ao melhoramento genético do cafeeiro em relação à escolha de cultivares tolerantes ao déficit hídrico. 


\section{Agradecimentos}

Os autores agradecem ao CNPq pelas bolsas e auxilio financeiro concedidos.

\section{Referências}

BLISKA, F. M. M. et al. Custo de produção do café nas principais regiões produtoras do país. Informações Econômicas, v. 39, n. 09, p. 5-20, 2009.

BRASIL. Ministerio da Agricultura, Pecuária e Abastecimento. Informe estatístico do café. Brasil, 2009.

CASTRO, E. M.; PEREIRA, F. J.; PAIVA, R. Histologia Vegetal: Estrutura e Função de Órgãos Vegetativos. Lavras: UFLA, 2009. $234 \mathrm{p}$.

COELHO, G. et al. Efeito de épocas de irrigação e de parcelamento de adubação sobre a produtividade do cafeeiro 'Catuaí'. Ciência e Agrotecnologia, v. 33, n. 01, p. 67-73, 2009.

DA MATTA, F. M. Exploring drought tolerance in coffee: a physiological approach with some insights for plant breeding. Brazilian Journal of Plant Physiology, v. 16, n. 01, p. 1-6, 2004.

DA MATTA, F. M. et al. Ecophysiology of coffee growth and production. Brazilian Journal of Plant Physiology, v. 19, n. 04, p. $485-510,2007$.

GOLBERG, A. D. et al. Effects and after-effects of water stress on chlorophyll fluorescence transi-entsin Coffea canephora Pierre and Coffea arabusta Capot and Aké Assi. Café Cacao Thé, v. 32, n. 01, p. 11-16, 1988.

GRISI, F. A. et al. Avaliações anatômicas foliares em mudas de café 'Catuaí' e 'Siriema' submetidas ao estresse hídrico. Ciência e Agrotecnologia, v. 32, n. 06, p. 1730-1736, 2008.

GUIMARÃES, R. J. et al. Cafeicultura. Lavras: UFLA/ FAEPE, 2002. 317 p.

GuimarãeS, R. J.; MENDES, A. N. G. Produção de mudas de cafeeiro. In: UFLA/FAEPE. (Org.). Produção e gerenciamento do café: Programa Treina Café. Lavras: FAEPE, 1999. cap.1, p. 2-18.
JONES, H. G. Plants and microclimate. 2. ed. New York: Cambridge University, 1992. 428 p.

MELLO, E. V. Cafeicultura no Brasil. In: ZAMBOLIM, L. Tecnologias de produção de café com qualidade. Viçosa: UFV, 2001. p. 565-646.

MELO, H. C. et al. Alterações anatômicas e fisiológicas em Setaria anceps Stapf ex Massey e Paspalum paniculatum L. sob condições de déficit hídrico. Hoehnea, v. 34, n. 02, p. 145-153, 2007.

MENDES, R. M. S. et al. Relações fonte-dreno em feijãode-corda submetido à deficiência hídrica. Revista Ciência Agronômica, v. 38, n. 01, p. 95-103, 2007.

MOREIRA, M. A.; ADAMI, M.; RUDORFF, B. F. T. Análise espectral e temporal da cultura do café em imagens Landsat. Pesquisa Agropecuária Brasileira, v. 39, n. 03, p. 223-231, 2004.

NASCIMENTO, E. A. et al. Alterações morfofisiológicas em folhas de cafeeiro (Coffea arabica L.) consorciado com seringueira (Hevea brasiliensis Muell. Arg.). Ciência Rural, v. 36, n. 03, p. 852-857, 2006.

PEREIRA, F. J. et al. Evolução da anatomia radicular do milho 'Saracura' em ciclos de seleção sucessivos. Pesquisa agropecuária Brasileira, v. 43, n. 12, p.1649-1656, 2008.

PINHEIRO, H. A. et al. Drought tolerance is associated with rooting depth and stomatal control of water use in clones of Coffea canephora. Annals of Botany, v. 96, n. 01, p. 101-108, 2005.

PINTO, C. M. et al. Crescimento, distribuição do sistema radicular em amendoim, gergelim e mamona a ciclos de deficiência hídrica. Revista Ciência Agronômica, v. 39, n. 03, p. 429-436, 2008.

RAMIRO, D. A. et al. Anatomical characterization of leaves from coffee plants resistant and susceptible to leaf miner. Bragantia, v. 63 , n. 03 , p. $363-367,2004$

SILVA, L. M.; ALQUINI, Y.; CAVALLET, V. J. Interrelações entre a anatomia vegetal e a produção vegetal. Acta Botânica Brasílica, v. 19, n. 01, p. 183-194, 2005.

SILVA, C. A. et al. Produtividade e potencial hídrico foliar do cafeeiro 'Catuai' em função da época de irrigação. Revista Brasileira de Engenharia Agrícola e Ambiental, v. 12, n. 01, p. 21-25, 2008. 